\title{
Diagnóstico intraoperatório de esquistossomose mansônica cerebelar pseudotumoral
}

\author{
Intraoperative diagnosis of pseudotumoral cerebellar neuroschistosomiasis
}

Maria Serapião'; Carlos Serapião²; André Kiss; Hamilton Appel ${ }^{4}$

\section{unitermos \\ Neuroesquistossomose \\ Pseudotumor cerebelar \\ Método do esmagamento linear (squash)}

\section{resumo}

A esquistossomose é uma doença parasitária causada por vermes trematódios do gênero Schistosoma. Esses vermes habitam ramos da veia mesentérica inferior e, por meio da ovoposição, disseminam seus ovos por várias regiões do organismo humano. O sistema nervoso central (SNC) pode ser afetado no decorrer de qualquer forma clínica da infecção, principalmente pela embolização dos ovos ocorrida após a migração anômala dos vermes adultos para locais próximos ao tecido cerebral. No SNC, os ovos induzem reação granulomatosa periovular intensa, respondendo pela produção do efeito de massa com sinais neurológicos de aumento de pressão intracraniana. É relatado o caso de um homem de 27 anos cujo diagnóstico de esquistossomose mansônica cerebelar foi obtido pelo método de esmagamento linear (squash), durante o ato cirúrgico. Uma biópsia retal realizada posteriormente confirmou a presença de ovos viáveis de S. mansoni. No conhecimento dos autores, este é o primeiro relato de neuroesquistossomose diagnosticado por esta técnica.

\section{abstract}

Schistosomiasis is a parasitic infection caused by trematode platyhelminths of the genus Schistosoma. These worms live in branches of the inferior mesenteric vein and disseminate its eggs to several regions of the human organism through circulation. Central nervous system (CNS) involvement may occur in the development of any clinical infection, mainly by in-situ egg deposition following anomalous migration of adult worms to sites near the cerebral tissue. The presence of eggs in the CNS induces a severe periovular granulomatous reaction, which is responsible for the mass effect and the increased intracranial pressure. A case of cerebellar schistosomiasis caused by S. mansoni in a 27-year-old man is diagnosed by squash (smear) technique. A rectal biopsy performed later showed viable S. mansoni eggs. This is, probably, the first report of neuroschistosomiasis diagnosed by the squash (smear) technique. key words

Neuroschistosomiasis

Squash (smear) method

Cerebellum pseudotumor.

1. Professora convidada de Anatomia Patológica da Universidade Federal do Paraná (UFPR). 


\section{Introdução}

A esquistossomose, em seus diversos tipos e apresentações, é uma parasitose endêmica em 74 países. Estima-se que afete 300 milhões de indivíduos em todo mundo, constituindo-se na segunda maior endemia parasitária mundial ${ }^{(1,7)}$.

Cinco espécies de esquistossomas são importantes para o homem, porém somente três foram descritas comprometendo o sistema nervoso central (SNC): S. mansoni, S. haematobium e S. Japonicum ${ }^{(10)}$. Dessas espécies, o Schistosoma mansoni é a única existente nas Américas e, no Brasil, atingiu cerca de 10 a 12 milhões de indivíduos, estando, graças a programas especiais de controle, reduzida agora para menos de 5 milhões. Sua ocorrência está diretamente ligada às condições precárias de saneamento básico que favorecem a contaminação da água pelos ovos eliminados nas fezes humanas em áreas onde existe o hospedeiro intermediário ${ }^{(6)}$.

Há uma preponderância de S. japonicum acometendo o encéfalo e S. mansoni e S. hematobium, a medula espinhal ${ }^{(1,2)}$. Em 1963, Marcial-Rojas et al., por meio de uma revisão da literatura, agruparam 97 casos de envolvimento do SNC por Schistosoma. Desses, 26 por S. mansoni, dos quais 17 envolviam a medula espinhal e nove o cérebro ${ }^{(7)}$.

O comprometimento do cerebelo é referido por Bambirra et al.(2), Brito et al.(4), Cabral e Pittella ${ }^{(5)}$ Raso et al.(11) e Silva et al. ${ }^{(13)}$, sendo que todos estes pacientes foram submetidos à cirurgia com ressecção da lesão.

\section{Relato de caso}

Paciente do sexo masculino com 27 anos relata história recente de cefaleia progressiva acompanhada de náuseas, vômitos e síndrome vertiginosa. Na época, o exame neurológico e a tomografia computadorizada (TC) de crânio foram normais. $\mathrm{O}$ estudo do liquor cefalorraquidiano (LCR) evidenciou pleocitose linfocitária e hiperproteinorraquia.

Um mês depois, o paciente foi internado no Serviço de Neurologia e Neurocirurgia do Hospital Dona Helena, em Joinville-SC, com quadro de cefaleia, ataxia de marcha com látero-pulsão à direita, nistagmo horizontal e paresia de nervo abducente direito. Dois meses depois foi realizada nova TC por persistência dos sintomas, a qual evidenciou lesão expansiva em fossa posterior, sugestiva de processo neoplásico primário do SNC. A ressonância magnética
(RM) cranioencefálica confirmou uma lesão infiltrativa de "vérmis" e hemisfério cerebelar direito estendendo-se para a ponte e o pedúnculo cerebral direito, compatível com processo expansivo primário do SNC (Figura 1).

O paciente foi submetido a microcirurgia estereotáxica e o exame anatomopatológico intraoperatório diagnosticou neuroesquistossomose mansônica sob a forma tumoral



Figura 1 - A: TC com contraste evidenciou lesão expansiva com impregnação nodular no vérmis e no hemisfério cerebelar direito; $B: R M$ ponderada em T2 evidenciou lesão expansiva com hipersinal na topografia do vérmis, do hemisfério cerebelar direito, à direita da ponte e do pedúnculo cerebral direito; C: RM ponderada em T1 após uso de contraste paramagnético evidenciou impregnação nodular heterogênea da lesão; $D$ : RM pós-operatória com cortes axiais em T2 evidenciando pequena área de hipersinal no hemisfério cerebelar direito sem efeito de massa; E: RM pós-operatória com cortes coronais em $T 1$ após contraste evidenciando pequeno realce nodular no hemisfério cerebelar direito e sugerindo reação granulomatosa residual

cerebelar pela técnica de esmagamento linear (squash). Posteriormente, o restante da amostra foi fixado em formaldeído, incluído em parafina e examinado em preparados histológicos corados por hematoxilina e eosina (HE). O diagnóstico foi complementado por biópsia retal realizada a seguir, que identificou ovos viáveis de S. mansoni (Figura 2).

O paciente foi tratado com praziquantel e dexametasona e estava assintomático na ocasião da alta hospitalar. 


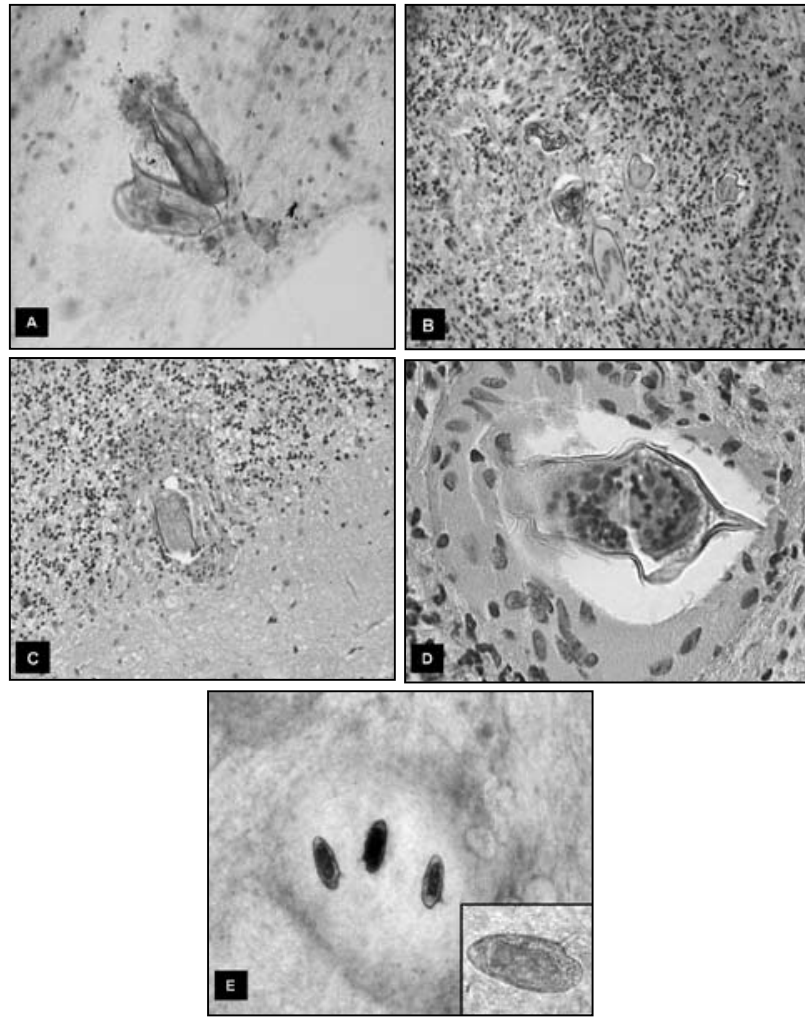

Figura 2 - A: Esmagamento linear (HE 200X) - ovos evidentes e preservados em meio a tecido cerebelar e células inflamatórias; B: cerebelo (HE) 200X - cortical cerebelar contendo numerosos granulomas constituídos por histiócitos e gigantócitos envolvendo ovos de Schistosoma mansoni; C: cerebelo H.E. (HE 200X) - ovos presentes entre as camadas molecular e granular interna; D: cerebelo (HE 400X) - granuloma com gigantócito multinucleado contendo ovo espiculado; E: reto - biópsia retal por vitrotransparência mostra numerosos ovos no sombreado de um granuloma. Encarte: detalhe do ovo com espícula lateral

\section{Discussão}

A esquistossomose mansônica é causada pelo trematódeo Schistosoma mansoni, que requer caramujos de água doce do gênero Biomphalaria como hospedeiro intermediário para completar o seu ciclo de desenvolvimento. A doença é transmitida pelos ovos de S. mansoni eliminados pelas fezes do hospedeiro infectado.

O contato humano com águas infectadas pelas cercárias é o modo pelo qual o indivíduo adquire a esquistossomose. Após a penetração, a larva resultante, denominada esquistossômulo, alcança a circulação venosa e, posteriormente, os pulmões. A partir daí o verme pode alcançar o sistema porta pela via hematogênica ou transtissular descrita em ratos por Wilks et al.(14). Uma vez no sistema porta intra-hepático, os esquistossômulos se desenvolvem, adquirindo a forma adulta, e migram para o território da veia mesentérica inferior, onde a fê- mea fará a ovoposição. Por intermédio das anastomoses entre as veias mesentérica inferior e pudenda interna os ovos podem alcançar os pulmões, a grande circulação e, posteriormente, atingir órgãos bem vascularizados como o SNC. A disseminação dos ovos ao SNC pode ocorrer também pela comunicação entre o sistema mesentérico portal e o plexo venoso epidural vertebral de Batson. Outro mecanismo é pela migração anômala de vermes adultos até locais próximo ao SNC seguida de ovoposição, que parece ser a principal maneira de se adquirir neuroesquistossomose $\mathrm{e}^{(10)}$.

A patogenia das lesões do SNC produzidas pelo Schistosoma depende da resposta imune do hospedeiro aos ovos do parasita, os quais se localizam, preferencialmente, nas estruturas mais ricamente vascularizadas. No SNC essas estruturas são: leptomeninge, córtex cerebral, gânglios da base, cerebelo, plexo coroide e medula espinhal.

A neuroesquistossomose mansônica afeta, preferencialmente, a medula espinhal, como relatado por diversos trabalhos ${ }^{(1,2)}$. O presente caso representa uma rara forma da neuroesquistossomose com comprometimento cerebelar se exteriorizando clinicamente sob a forma de tumor primitivo. A forma tumoral da esquistossomose cerebelar encontra-se descrita na literatura em apenas 13 casos histologicamente confirmados, relatados de 1984 a 2007. Desses casos, 11 eram homens e duas mulheres, havendo variação de idade de 11 a 40 anos. A apresentação clínica dos casos relatados é semelhante à encontrada no presente caso. Em todos os pacientes, o exame anatomopatológico mostrou numerosos granulomas por esquistossomose em várias fases evolutivas ${ }^{(10,11)}$. Não foi relatado, em nenhum desses trabalhos prévios, o emprego do método de esmagamento linear como técnica utilizada para o diagnóstico perioperatório da lesão.

A apresentação clínica da forma tumoral da neuroesquistossomose não se distingue muito daquela causada por processos intracranianos lentamente expansivos. Os ovos que alcançam o SNC formam grandes granulomas em área circunscrita, respondendo pela produção do efeito de massa com sinais neurológicos de aumento da pressão intracraniana. Não estão descritos sintomas neurológicos ou achados de TC específicos para o diagnóstico dessa enfermidade e, com exceção das alterações no exame neurológico, o exame físico é normal. Os exames laboratoriais são de pouca contribuição, mas a contagem de eosinófilos geralmente demonstra um número aumentado. 
A presença de ovos de S. mansoni nas fezes ou em biópsias retais é observação frequente. Em todos os relatos da literatura, o diagnóstico esteve fundamentado na identificação de ovos e granulomas no tecido nervoso removidos após cirurgia ou por autópsia ${ }^{(10,11)}$. Pittella e Lana-Peixoto( ${ }^{(9)}$ demonstraram que $26 \%$ de 46 pacientes com esquistossomose hepatoesplênica apresentavam extensa deposição de ovos no cérebro. Desses pacientes, apenas um apresentava sintomas neurológicos, levando a crer que a neuroesquistossomose seja mais frequente do que a expressividade clínica sugere. A impossibilidade de se estabelecer uma suspeita diagnóstica pré-operatória representa uma dificuldade para o patologista, a quem são fornecidos dados inespecíficos e não-indicativos da lesão. Deste modo, a possibilidade de que a afecção do SNC por ovos de esquistossoma tenha maior prevalência do que se supõe faz com que o reconhecimento microscópico seja de grande importância epidemiológica.

A técnica do diagnóstico intraoperatório por esmagamento linear dos fragmentos obtidos por cirurgia estereotáxica tem se mostrado procedimento muito importante no auxílio à atuação do cirurgião, havendo forte correlação com diagnósticos alcançados pelo uso da tradicional técnica de parafina. Vários trabalhos foram realizados com o objetivo de comparar os dois métodos no diagnóstico de neoplasias envolvendo o $\mathrm{SNC}^{(3,12)}$, porém as contribuições da literatura são escassas quando se referem a parasitismos do SNC. O uso de métodos intraoperatórios para o diagnóstico de esquistossomose está amplamente descrito na literatura mundial, porém, até o momento, não há referências ao uso do esmagamento linear (squash) no comprometimento do SNC pela esquistossomose.

A doença no SNC, como em qualquer órgão afetado pela esquistossomose, está constituída pela reação granulomatosa, apresentando três estágios clássicos de alteração tissular: necrótico-exudativo, produtivo e de cura por fibrose. No estágio necrótico-exudativo observam-se ovos viáveis ao redor dos quais ocorre extensa formação granulomatosa formada por zona central de necrose periovular e camada de células epitelioides e mononucleadas dispostas perifericamente. Já no estágio produtivo os ovos geralmente estão parcialmente vazios ou fragmentados, não há necrose e a reação inflamatória periovular consiste em células epitelioides e gigantes. O estágio de cura por fibrose apresenta granulomas menores do que os da fase produtiva e os ovos, frequentemente fragmentados, são envolvidos por células gigantes e poucas células epitelioides e linfócitos, ao lado de fibrose e reação astrocítica ${ }^{(10,11)}$. O caso em questão apresentou-se sob a forma produtiva, conforme demonstrado na Figura 2.

Considerando a grande prevalência de indivíduos infestados no Brasil, deve-se ressaltar a necessidade de divulgação intensa das mais variadas apresentações e métodos diagnósticos da neuroesquistossomose, bem como incluí-la na lista de possibilidades diagnósticas para a etiologia de manifestações clínicas neurológicas.

\section{Referências}

1. ANDRADE, A. N. Neuroesquistossomose. Arq Neuropsiquiatr, v. 44, p. 275-9, 1986.

2. BAMBIRRA, E. A. et al. The tumoral form of schistosomiasis: report of a case with cerebellar involvement. Am J Trop Med Hyg, v. 33, p. 76-9, 1984.

3. BLEGGI-TORRES, L. F.; COLLAÇO, L. M. Smear technique for the intraoperative examination of nervous system lesions. Acta. Cytol, v. 37, p. 1, 34-9, 1993.

4. BRITO, D. M. M. et al. Esquistossomose cerebelar. Neurobiol, v. 56, p. 69-72, 1993.

5. CABRAL, G.; PITELLA, J. E. H. Tumoural form of cerebellar schistosomiais mansoni. Report of surgically treated case. Acta Neusochir, v. 99, p. 148-51, 1989.
6. FERREIRA, L. A. etal. Formatumoral encefálica esquistossomótica: apresentação de um caso tratado cirurgicamente. Rev Soc Bras Med Trop, v. 31, p. 89-93, 1998.

7. MARCIAL-ROJAS, R. A.; FIOL, R. E. Neurological complications of schistosomiasis. Review of the literature and report of two cases of transverse myelitis due to S. mansoni. Ann Intern Med, v. 59, p. 215-30, 1963.

8. PANIS, Y. et al. Appendiceal localization of bilharziasis: value of extemporaneous histological examination. Ann Chir, v. 48, p. 374-6, 1994.

9. PITTELLA, J. E. H.; LANA-PEIXOTO, M. A. Brain involvement in hepatosplenic schistosomiasis mansoni. Brain, v. 104, p. 621-32, 1981. 
10. PItTElLA, J. E. H. Neuroschistosomiasis. Brain Pathol, v. 7, p. 649-62, 1997.

11. RASO, P. etal. The tumoral form of cerebellar schistosomiasis: case report and measure of granulomas. Rev Soc Bras Med Trop, v. 39, p. 283-6, 2006.

12. SHAH, A. B. et al. Squash preparation and frozen section in intraoperative diagnosis of central nervous system tumors. Acta Cytol, v. 42, p. 1149-541, 1998.

13. SILVA, J. C. et al. Schistosomiasis mansoni presenting as a cerebellar tumor: case report. Arq Neuropsiquiatr, v. 65 , n. 3B, p. 845-7, 2007.

14. WILKS, N. E. Lung-to-liver migration of schistosomes in the laboratory mouse. Am J Trop Med Hyg, v. 16, p. 599-605, 1967. 